\title{
Nanoencapsulation of Nimodipine in Novel Biocompatible Poly(propylene-co-butylene succinate) Aliphatic Copolyesters for Sustained Release
}

\author{
Sofia Papadimitriou, ${ }^{1}$ George Z. Papageorgiou, ${ }^{1}$ Feras I. Kanaze, ${ }^{2}$ \\ Manolis Georgarakis, ${ }^{3}$ and Dimitrios N. Bikiaris ${ }^{1}$ \\ ${ }^{1}$ Laboratory of Organic Chemical Technology, Department of Chemistry, Aristotle University of Thessaloniki, Thessaloniki, \\ GR-541 24 Macedonia, Greece \\ ${ }^{2}$ Pharmathen S.A., Pharmaceutical Industry, Dervenakion Str 6, Pallini Attikis, 15351 Attiki, Greece \\ ${ }^{3}$ Section of Pharmaceutics and Drug Control, Department of Pharmacy, Aristotle University of Thessaloniki, Thessaloniki, \\ 54124 Macedonia, Greece
}

Correspondence should be addressed to Dimitrios N. Bikiaris, dbic@chem.auth.gr

Received 21 December 2008; Revised 14 July 2009; Accepted 19 August 2009

Recommended by Alan Fuchs

Biocompatible poly(propylene-co-butylene succinate) (PPBSu) copolyesters, containing up to 50 mol\% butylene succinate units, were synthesized by the two-stage melt polycondensation method (esterification and polycondensation). The copolymers were fully characterized and biocompatibility studies were also performed. They were proved to be biocompatible and they were used as polymer matrices for the preparation of drug loaded nanoparticles. Nimodipine was selected as a model hydrophobic poorly water soluble drug. From the results obtained by dynamic light scattering (DLS) and scanning electron microscopy (SEM), drug loaded copolymer nanoparticles were found to exhibit a spherical shape and their mean diameter appeared in the range of 180-200 $\mathrm{nm}$. Fourier Transformation-Infrared Spectroscopy (FTIR) spectra indicated that no chemical interaction between the drug and the matrix could be justified, while Wide-Angle X-Ray Diffraction (WAXD) patterns proved a low degree of crystallinity of Nimodipine in the nanoparticles. The release behavior of the model drug from nanoparticles was also investigated in order to identify modifications and find out any possible correlation between the chemical composition of the polymer matrix and the drug release rates.

Copyright ( $) 2009$ Sofia Papadimitriou et al. This is an open access article distributed under the Creative Commons Attribution License, which permits unrestricted use, distribution, and reproduction in any medium, provided the original work is properly cited.

\section{Introduction}

During the past decades an increasing interest on biomaterial research led to synthesis and application of new biocompatible and biodegradable polymers in the field of nanotechnology and in particular in the creation and use of biodegradable polymeric nanoparticles for drug delivery applications $[1,2]$. Incorporation of the drug into a particulate carrier can protect the active substance against degradation in vivo and in vitro, it also offers possibilities of targeting, improves the therapeutic effect, prolongs the biological activity, controls the drug release rate and decreases the administration frequency [3].

A number of different polymers, not only synthetic but also natural, have been used in formulating biodegradable nanoparticles. One of the most frequently used natural polymers for the preparation of drug loaded nanoparticles is chitosan [4-7]. The most widely used and studied class of biodegradable polymers is that of aliphatic polyesters, including poly(lactic acid), poly(glycolic acid), their copolymers and polycaprolactone (PCL) [8-10]. Towards this direction, synthesis, characterization and application of new polyesters as potential nanoparticle matrices for drug delivery applications, represent a great challenge for the scientists working in the related fields.

Poly(butylene succinate) (PBSu) is one of the most promising biodegradable polyesters. Thus in relatively recent works its crystal structure, crystallization and melting behavior were discussed as well as preparation of related copolymers and blends based on PBSu $[11,12]$. Unfortunately, the 
polymer, like PCL, shows rather slow biodegradation rate because of its high degree of crystallinity [13].

Poly(propylene succinate) (PPSu) is a relatively new biodegradable polymer produced using monomers from renewable resources [14-18]. PPSu has gained an increasing interest, since it has fast biodegradation rate, higher than poly(ethylene succinate) (PESu) or poly(butylene succinate) (PBSu) [13].

It is very important that it is also biocompatible [19]. In contrast to other biodegradable polyesters, a limited number of published works dealing with PPSu have been reported concerning only its properties and biodegradation rates [2025 ] while there is not any published work using PPSu as drug carrier.

In general copolymers are expected to show faster enzymatic hydrolysis rates. Also, copolymerization may result in formation of materials with reduced crystallinity and maybe allowing effective preparation of drug loaded nanoparticles prior to optimize drug release rates [26]. To our knowledge, the use of neither neat PPSu nor of any PPSu related copolymers in pharmaceutical applications has been reported, before.

The aim of this work was to investigate the potential use of copolymers related to the biocompatible and biodegradable PPSu in drug delivery systems. Thus, poly(propyleneco-butylene succinate) (PPBSu) copolymers were first synthesized, and then used to prepare drug loaded nanoparticles by $\mathrm{o} / \mathrm{w}$ solvent evaporation method. This method is usually suitable for loading lipophilic drugs. Here, Nimodipine, a second-generation dihydropyridine calcium antagonist with apparent selectivity for cerebral blood vessels, was used as a model hydrophobic drug to be encapsulated into the polymeric nanoparticles [27]. The chemical structures of the drug and copolymers are shown in Figure 1. Particle size distribution, encapsulation efficiency, solid state characterization of the entrapped drug, and its release rates from the nanoparticles were investigated using DLS (Dynamic Light Scattering), SEM (Scanning Electron Microscopy), FTIR, WAXD and HPLC. Biocompatibility of the copolymers was also studied.

\section{Materials and Methods}

2.1. Materials. The polyesters and copolyesters were synthesized from succinic acid and proper diol or mixture of diols. Succinic acid (purum 99\%) and 1,4-butanediol (purum $99 \%$ ) were purchased from Aldrich Chemical Co. 1,3-Propanediol (CAS Number: 504-63-2, Purity: >99,7\%) was kindly supplied by Du Pont de Nemours Co. Tetrabutyl titanate catalyst of analytical grade and polyphosphoric acid (PPA) used as heat stabilizer were purchased from Aldrich Chemical Co. Poly(DL-lactide) (PLA, molecular weight $M w=109 \times 103)$ was synthesized as described previously $[28,29]$. Micronized Nimodipine (Nimo) with an assay of $101.2 \%$, was supplied from UQUIFA (Spain). Sodium cholate was purchased from Acros Organics. All the other materials and solvents which were used for the analytical methods were of analytical grade.

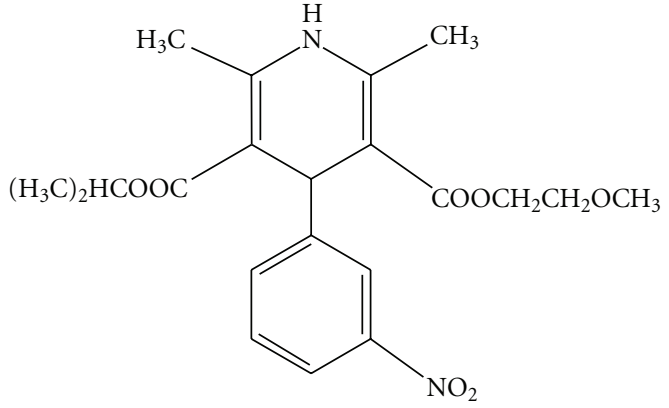

(a)

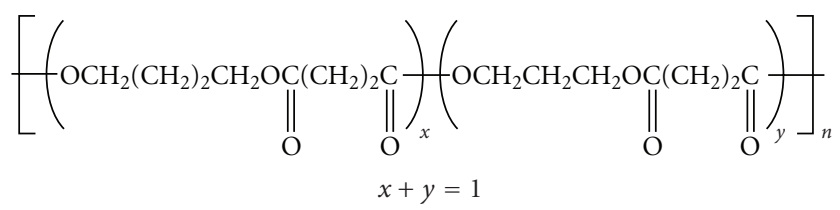

(b)

Figure 1: Chemical structure of (a) Nimodipine and (b) poly(propylene-co-butylene succinate) copolymers.

2.2. Synthesis of Polyesters. The aliphatic polyesters were prepared by the two-stage melt polycondensation method (esterification and polycondensation) in a glass batch reactor [30]. In brief, proper amount of succinic acid and appropriate glycols in a acid/diol molar ratio 1/1.1 using $\mathrm{Ti}(\mathrm{OBu})_{4}$ as catalyst, were charged into the reaction tube of the polyesterification apparatus. The apparatus with the reagents was evacuated several times and filled with argon in order to remove the whole oxygen amount. The reaction mixture was heated at $180^{\circ} \mathrm{C}$ under argon atmosphere and stirring at a constant speed $(500 \mathrm{rpm})$. In this first step (esterification) $\mathrm{H}_{2} \mathrm{O}$ was formed, and was removed from the reaction mixture by distillation.

In the second step of polycondensation, PPA was added $\left(5 \times 10^{-4} \mathrm{~mol} \mathrm{PPA} / \mathrm{mol} \mathrm{SA}\right)$, which is believed to prevent side reactions such as etherification and thermal decomposition. A vacuum $(5.0 \mathrm{~Pa})$ was applied slowly over a period of time of about 30 minutes, to avoid excessive foaming and to minimize oligomer sublimation, which is a potential problem during the melt polycondensation. The temperature was slowly increased to $230^{\circ} \mathrm{C}$ while stirring speed was increased to $720 \mathrm{rpm}$. The polycondensation continued for about 60 minutes for all prepared polyesters.

2.3. Polymer Characterization. Intrinsic viscosity measurements on the isolated polymers were performed using an Ubbelohde viscometer $\mathrm{Oc}$ at $25^{\circ} \mathrm{C}$ in chloroform, at a solution concentration of $1 \mathrm{wt} \%$.

Molecular weight determinations were performed by GPC (Gel Permeation Chromatography) method, using a Waters 150C GPC, equipped with differential refractometer as detector and three ultrastyragel $(103,104,105 \AA)$ columns in series. THF (Tetrahydrofuran) was used as the eluent $(1 \mathrm{~mL} / \mathrm{min})$ and the measurements were performed at $35^{\circ} \mathrm{C}$. 
Calibration was performed using polystyrene standards with a narrow molecular weight distribution.

${ }^{1} \mathrm{H}-\mathrm{NMR}$ spectra of polyesters were obtained with a Bruker spectrometer operating at a frequency of $400 \mathrm{MHz}$ for protons. Deuterated chloroform $\left(\mathrm{CDCl}_{3}\right)$ was used as solvent in order to prepare solutions of $5 \% \mathrm{w} / \mathrm{v}$. The number of scans was 10 and the sweep width was $6 \mathrm{kHz}$.

A Perkin-Elmer, Pyris 1 differential scanning calorimeter (DSC), calibrated with Indium and Zinc standards, was used. Samples of $5 \pm 0.1 \mathrm{mg}$ were used in tests. They were sealed in aluminium pans and heated to $30^{\circ} \mathrm{C}$ above the melting point at a heating rate $20^{\circ} \mathrm{C} / \mathrm{min}$. The samples were held at that temperature for 5 minutes in order to erase any thermal history and then they were cooled in the instrument by $200^{\circ} \mathrm{C} / \mathrm{min}$ to $-50^{\circ} \mathrm{C}$. Subsequent heating scans of the quenched samples were recorded to observe the glass transition temperature. Heating rate was in most tests $20^{\circ} \mathrm{C} / \mathrm{min}$. If some other rate was used this will be discussed in the specific section.

WAXD was used for the identification of the crystal (structure and changes) of the polymers and also the drug in case of nanoparticle samples. WAXD study was performed over the range $2 \theta$ from 5 to $50^{\circ} \mathrm{C}$, using a Philips PW 1710 diffractometer with Bragg-Brentano geometry $(\theta, 2 \theta)$ and $\mathrm{Ni}$-filtered CuKa radiation.

\subsection{Preparation of Drug-Loaded PPBSu Copolymer Nanopar-} ticles. The PPBSu copolymer nanoparticles were prepared by $\mathrm{o} / \mathrm{w}$ solvent evaporation method. $100 \mathrm{mg}$ of copolymer and $10 \mathrm{mg}$ Nimodipine were dissolved in $2 \mathrm{~mL}$ dichloromethane. This solution was transferred to an aqueous solution of sodium cholate $(V=6 \mathrm{~mL}, C=12 \mathrm{mV})$ and the mixture was probe sonicated for 1 minute $[28,29]$. The $\mathrm{o} / \mathrm{w}$ emulsion formed was gently stirred and $\mathrm{CH}_{2} \mathrm{Cl}_{2}$ was allowed to evaporate. The nanoparticles were purified by centrifugation (9500 rpm, or equivalently $6000 \mathrm{~g}$, for $20 \mathrm{~min}$ ). The samples were reconstituted with deionized water. The suspension was filtered by a microfilter with pore size of $1.2 \mu \mathrm{m}$ in order to remove polymer aggregates.

\subsection{Characterization of Drug-Loaded Nanoparticles}

2.5.1. SEM Measurements of the Nanoparticles. The morphological examination of Nimodipine loaded nanoparticles was performed using a scanning electron microscope (SEM) system Jeol JMS 840 (Tokyo, Japan). The samples were covered with carbon coating to increase conductivity of the electron beam.

2.5.2. Mean Particle Size Determination. The particle size distribution of nanoparticles was determined by dynamic light scattering (DLS) using a Zetasizer Nano Instrument (Malvern Instruments, Nano ZS, ZEN3600, UK) operating with a $532 \mathrm{~nm}$ laser. A suitable amount of nanoparticles was dispersed in distilled water creating a total concentration $1 \%$ and was kept at $37^{\circ} \mathrm{C}$ under agitation at $100 \mathrm{rpm}$. All the measurements were repeated 3 times and the mean size and size distribution were determined. Values reported are the mean diameter \pm SD for three replicate samples.
2.5.3. Nanoparticles Yield, Drug Loading Content, and Entrapment Efficiency. The obtained micellar solutions were frozen and lyophilized by freeze drier system to obtain dried nanoparticle product. The samples were analyzed by an HPLC method. The mobile phase used was Acetonitrile/water $(65: 35, \mathrm{v} / \mathrm{v})$, and Nimodipine was detected at $236 \mathrm{~nm}$. The flow rate of the mobile phase was $1 \mathrm{ml} / \mathrm{min}$ and the column temperature was $40^{\circ} \mathrm{C}$. The presence of polymers did not interfere with the chromatographic analysis of nimodipine.

The nanoparticles yield, drug loading, and drug entrapment efficiency were presented by following equations, respectively,

Nanoparticles Yield (\%)

$$
=\frac{\text { weight of nanoparticles }}{\text { weight of polymer and drug fed initially }} \times 100,
$$

Drug Loading Content (\%)

$$
=\frac{\text { weight of drug in nanoparticles }}{\text { weight of nanoparticles }} \times 100 \text {, }
$$

Entrapment Effciency (\%)

$$
=\frac{\text { weight of drug in nanoparticles }}{\text { weight of drug fed initially }} \times 100 \text {. }
$$

2.5.4. Fourier Transformation-Infrared Spectroscopy. FTIR spectra of freeze dried nanoparticles were obtained using a Perkin-Elmer FTIR spectrometer, model Spectrum 1000. In order to collect the spectra, a small amount of each material was used (1 wt\%) and compressed in KBr tablets. The IR spectra, in absorbance mode, were obtained in the spectral region of 450 to $4000 \mathrm{~cm}^{-1}$ using a resolution of $4 \mathrm{~cm}^{-1}$ and 64 co-added scans.

2.6. In Vitro Drug Release Studies of Drug-Loaded Nanoparticles. A dissolution apparatus I (baskets) of USP DISTEK 2100C was used, equipped with DISTEK syringe pump and dissolution sampler. Appropriate amounts of each drugloaded nanoparticle suspensions, equivalent to $5 \mathrm{mg}$ of nimodipine were placed in a dialysis cellulose membrane bag, with a molecular weight cut-off 12.400 , tied, and placed into the baskets. In order to avoid a situation where a false idea of release profile arises, before the use of the cellulose membrane, it remains in agitation, overnight, into the buffer solution at $37^{\circ} \mathrm{C}$. Also the nanoparticles are resuspended into the membrane with the use of $1 \mathrm{~mL}$ of the release medium. The tests were performed according to the method described in European Pharmacopoeia 4005000 at $37 \pm$ $0.5^{\circ} \mathrm{C}$ and $100 \mathrm{rpm}$, using $500 \mathrm{~mL}$ phosphate buffer saline $\mathrm{pH} 7.4$ containing $20 \%$ ethanol as a dissolution medium $[31,32]$ Samples of $4 \mathrm{~mL}$ were collected using an automatic sampler type Distek Evolution 4300, filtered by nylon filters (Whatman $0.45 \mu \mathrm{m}$ ) and analyzed, as described above using the same HPLC method. Each test was performed in triplicate while the RSD was found to be less than 3\%. 
TABle 1: Composition of PPBSu copolymers determined from ${ }^{1} \mathrm{H}$ NMR spectra, intrinsic viscosities and molecular weight values.

\begin{tabular}{lccccc}
\hline Polyester & $\begin{array}{c}\text { PSu/BSu } \\
(\mathrm{mol} \%)^{*}\end{array}$ & $\begin{array}{c}{[\eta]} \\
(\mathrm{dL} / \mathrm{g})\end{array}$ & $\begin{array}{c}\mathrm{Mn} \\
(\mathrm{g} / \mathrm{mol})\end{array}$ & $\begin{array}{c}M w \\
(\mathrm{~g} / \mathrm{mol})\end{array}$ & $M w / \mathrm{Mn}$ \\
\hline PPBSu 100/0 & $100 / 0$ & 0.63 & 18630 & 42850 & 2.30 \\
PPBSu 90/10 & $88.6 / 11.4$ & 0.61 & 17800 & 39160 & 2.20 \\
PPBSu 80/20 & $84.6 / 15.1$ & 0.73 & 21340 & 44800 & 2.10 \\
PPBSu 70/30 & $70.7 / 29.1$ & 0.73 & 21880 & 47040 & 2.15 \\
PPBSu 60/40 & $60.6 / 39.4$ & 0.66 & 19360 & 42590 & 2.20 \\
PPBSu 50/50 & $53 / 47$ & 0.65 & 18900 & 42530 & 2.25 \\
\hline
\end{tabular}

${ }^{*}$ Composition determined by ${ }^{1} \mathrm{H}$ NMR.

2.7. Cell Culture. The human umbilical vein endothelial cells (HUVEC) were grown routinely in RPMI-1640 medium supplemented with 15\% fetal bovine serum (FBS), 15 mg ECGS, $100 \mathrm{U} / \mathrm{mL}$ penicillin, $100 \mu \mathrm{g} / \mathrm{mL}$ streptomycin, $50 \mu \mathrm{g} / \mathrm{mL}$ gentamycin and $2.5 \mu \mathrm{g} / \mathrm{mL}$ amphotericin B. Cultures were maintained at $37^{\circ} \mathrm{C}, 5 \% \mathrm{CO}_{2}$ and $100 \%$ humidity.

2.8. In Vitro Biocompatibility Study. The biocompatibility of PPSu and its PPBSu copolymers, in comparison to biocompatible PLA, was evaluated by measuring the viability of HUVEC cells in the presence of different concentrations of the polymers $[28,29]$. Cell viability was determined by the MTT assay. HUVEC cells were seeded in 24-well plates at a density of 30.000 cells per well in $500 \mu \mathrm{L}$ cell culture medium. Twenty-four hours after plating, different amounts of copolymer, PPBSu, nanoparticles (suspended in water) were added in the wells. In case of the control sample consisted of the biocompatible polymer PLA, the method for the preparation of the PLA nanoparticle was simple solvent evaporation technique, the same procedure for the preparation of the drug loaded nanoparticles but without the use of the drug. Also the nanoparticle size, as in case of the other copolymers vary between 180 and $200 \mathrm{~nm}$. After 24 hours of incubation at $37^{\circ} \mathrm{C}, 50 \mu \mathrm{L}$ of MTT solution $(5 \mathrm{mg} / \mathrm{mL}$ in PBS pH 7.4) were added into each well and plates were incubated at $37^{\circ} \mathrm{C}$ for 2 hours. The medium was withdrawn and $200 \mu \mathrm{L}$ acidified isopropanol $(0.33 \mathrm{~mL}$ $\mathrm{HCl}$ in $100 \mathrm{~mL}$ isopropanol) were added in each well and agitated thoroughly to dissolve the formazan crystals. The solution was transferred to 96-well plates and immediately read on a microplate reader (Biorad, Hercules, CA, USA), at a wavelength of $490 \mathrm{~nm}$. The experiments were performed in triplicate. Biocompatibility of polymers was expressed as $\%$ cell viability, which was calculated from the ratio between the number of cells treated with the nanoparticles and that of nontreated cells (control).

\section{Results and Discussion}

3.1. Synthesis Preparation and Characterization of PPBSu Copolymers. The PPSu, PBSu homopolyesters and the PPBSu copolyesters were synthesized following the two-step polycondensation method. It should be noted that synthesis
TABLE 2: Transition temperatures and crystallinity of PPBSu copolymers crystallized from the melt during storage at room temperature for two months.

\begin{tabular}{lccc}
\hline Sample & $T_{m}\left({ }^{\circ} \mathrm{C}\right)$ & $T_{g}\left({ }^{\circ} \mathrm{C}\right)$ & $X c, \%(\mathrm{X}$-ray $)$ \\
\hline PPBSu 100/0 & 49 & -31 & 25.6 \\
PPBSu 90/10 & 42 & -32 & 22.1 \\
PPBSu 80/20 & amorphous & -33 & 0.0 \\
PPBSu 70/30 & amorphous & -35 & 0.0 \\
PPBSu 60/40 & 47 & -36 & 13.4 \\
PPBSu 50/50 & 58 & -37 & 19.6 \\
\hline
\end{tabular}

was carried out directly from succinic acid and not from its dimethylester. The composition of the copolyesters was elucidated from the ${ }^{1} \mathrm{HNMR}$ spectra using the relative intensities of the proton peaks arising from butylene succinate (BSu) and propylene succinate (PSu) repeating units and the results are given in Table 1 . Some deviation of the composition of the copolymers was found from the expected given the diol ratio in the feed of the reactor. It must be noted here that, albeit the precise molar composition was determined from ${ }^{1} \mathrm{HNMR}$ spectra, in the following, the samples will be referred to using the 1,3-propanediol/1,4-butanediol weight ratios in the reactor feed, for simplicity.

The molecular weights of the prepared polyesters were determined from the intrinsic viscosity measurements as well as by GPC. It can be seen from Table 1 that the synthesized copolymers had high and similar molecular weights. The DSC traces of the samples crystallized from the melt at room temperature are shown in Figure 2(a). As can be seen the melting points $\left(T_{m}\right)$ of the copolyesters decreased with increasing comonomer content. The PPBSu $80 / 20$ and $70 / 30 \mathrm{w} / \mathrm{w}$ copolymers did not crystallize from the melt on storage at room temperature. However, the chemical structure of the sample does not favor crystallization. Crystallization is very slow even for the neat PPSu, due to the presence of propylene segments and the odd number of methylene groups in the repeating unit of the polyester, resulting in reduced symmetry along the chains due to conformational limitations. As a matter of fact, introduction of a significant amount of comonomer units into the copolymer chains reduces further the symmetry and crystallizability. Figure 2(b) shows the DSC heating traces of the amorphous copolymer samples. Some slight drop of the glass transition temperature $\left(T_{g}\right)$ is observed with increasing the portion of butylene groups in the copolymers (Table 2). The $T_{g} s$ varied in between the two values for the neat PPSu and neat $\mathrm{PBSu}$, which were $-31^{\circ} \mathrm{C}$ and $-43^{\circ} \mathrm{C}$, respectively.

WAXD patterns showed that copolymers had lower crystallinity. Thus, the PPBSu 80/20 and 70/30 w/w samples proved to be amorphous, as only the amorphous halos were observed in the respective patterns (Figure 3). Also important is that the PPBSu $60 / 40$ and $50 / 50 \mathrm{w} / \mathrm{w}$ copolymers crystallized forming PBSu like crystals. Thus, among the copolyesters only the PPBSu 90/10 w/w gave PPSu like crystals. 


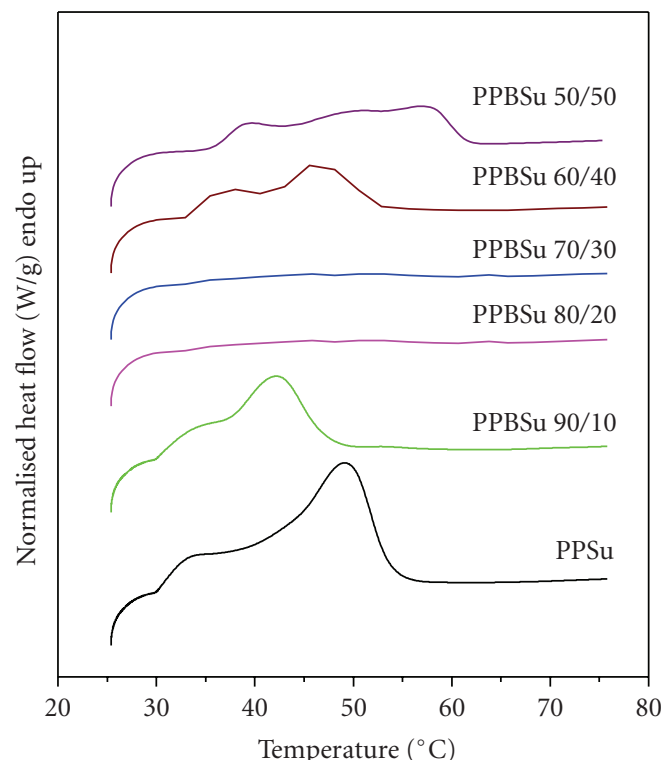

(a)

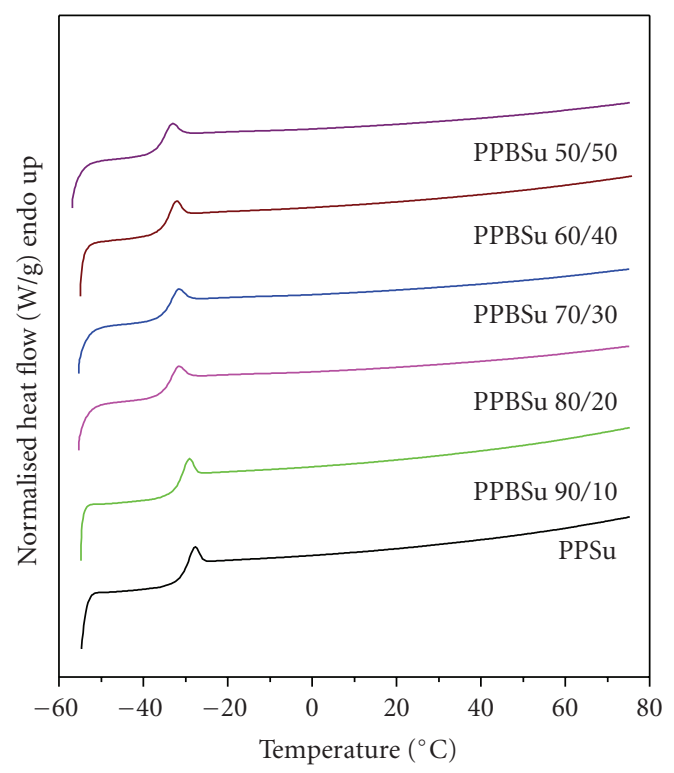

(b)

FIGURE 2: DSC heating traces for (a) semicrystalline and (b) amorphous PPBSu copolymers.

3.2. Morphology and Size Distribution of Drug-Loaded Nanoparticles. Particle size is an important parameter as it affects the drug release, the physical stability and the cellular uptake. Many factors seem to influence the particle size in similar copolyester nanoparticles, like the polymer molecular weight and the capability from different polyesters for drug loading. Data for the size of the nanoparticles are listed in Table 3. As has been previously reported for PLGA nanoparticles an increase in molecular weight leads to the increase of nanoparticles size [33]. In this case PPBSu copolyesters have approximately the same molecular weight, and it would be expected to give almost the same

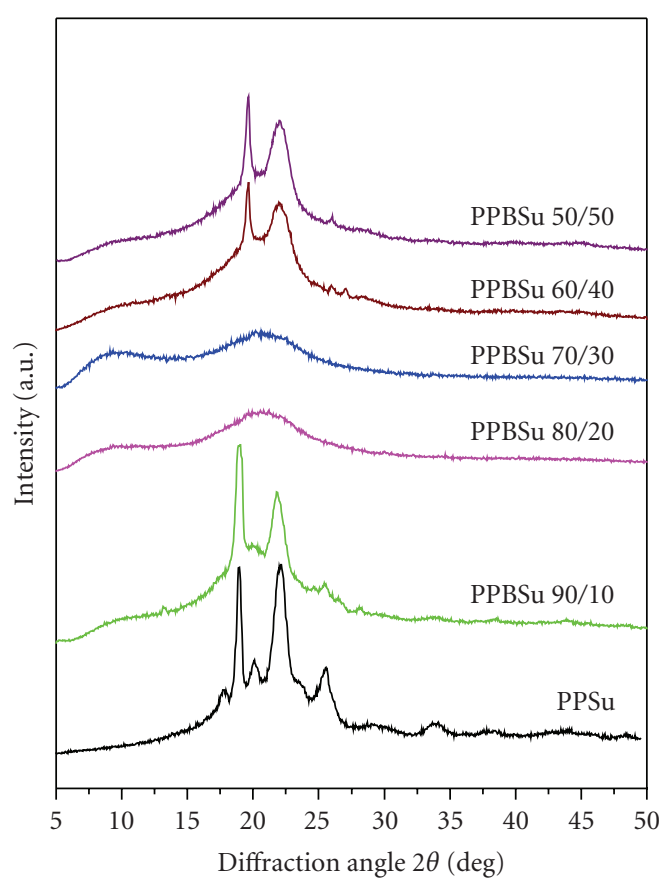

Figure 3: WAXD patterns for the PPBSu copolymers.

nanoparticle size. Nevertheless for the samples of PPBSu $50 / 50$ and 70/30 the nanoparticle size appears at $210 \mathrm{~nm}$ while PPBSu 90/10 and 60/40 show the smaller particle size at $180 \mathrm{~nm}$ (Table 3). It has also been reported for copolymers that the particle size increases with increasing the content in hydrophobic comonomer sequences [34]. For PPBSu copolymers however no effect was observed with increasing butylene succinate content of copolymers. Poly(butylene succinate) is expected to be more hydrophobic than poly(propylene succinate). From Table 3 it could be concluded that the mean diameter shows no systematic change with the chemical composition of the copolymers and in all cases the mean diameter was roughly $200 \mathrm{~nm}$.

Figure 4 shows the particle size distributions of PPBSu Nimodipine loaded nanoparticles as determined by dynamic light scattering (DLS). It is obvious that nanoparticles in all cases of copolymers show a unimodal size distribution, the sample of PPBSu 60/40 to give the narrowest distribution. The mean diameter varied from 180 to $200 \mathrm{~nm}$.

In order to characterize the morphology of the copolymer nanoparticles, scanning electron microscopy measurements were carried out. SEM photographs of nanoparticles are shown in Figure 5. Photographs showed that most of the drug-loaded nanoparticles had a regular spherical shape with a diameter about $200 \mathrm{~nm}$ or less, a fact that is in agreement with the measurements of dynamic light scattering.

3.3. Evaluation of Nanoparticles Yield, Drug Loading, and Entrapment Efficiency. Table 3 also summarizes the nanoparticle yield, drug loading content and entrapment efficiency of PPBSu nanoparticles. These parameters can be affected by many factors, such as molecular weight, the ratio of 
TABLE 3: Nanoparticle Yield, drug loading, entrapment efficiency and mean diameter of Nimodipine loaded PPBSu nanoparticles.

\begin{tabular}{|c|c|c|c|c|c|}
\hline Sample & Drug Loading (\%) & Entrapment Efficiency (\%) & Micelle Yield (\%) & Mean Diameter (nm) & PdI* \\
\hline PPBSu $100 / 0$ & 8.43 & 72.9 & $75.77 \pm 4.92$ & $191.5 \pm 13.43$ & 0.167 \\
\hline PPBSu 90/10 & 9.07 & 85.0 & $75.44 \pm 6.39$ & $180.5 \pm 7.78$ & 0.174 \\
\hline PPBSu 80/20 & 9.05 & 83.0 & $78.95 \pm 1.61$ & $190 \pm 4.24$ & 0.112 \\
\hline PPBSu 70/30 & 8.56 & 73.6 & $78.78 \pm 0.62$ & $210 \pm 5.66$ & 0.179 \\
\hline PPBSu 60/40 & 8.75 & 72.7 & $77.44 \pm 2.57$ & $182.5 \pm 10.61$ & 0.132 \\
\hline PPBSu 50/50 & 8.09 & 69.7 & $76.91 \pm 2.11$ & $210.5 \pm 0.71$ & 0.140 \\
\hline
\end{tabular}

* PdI: Polydispersity Index.

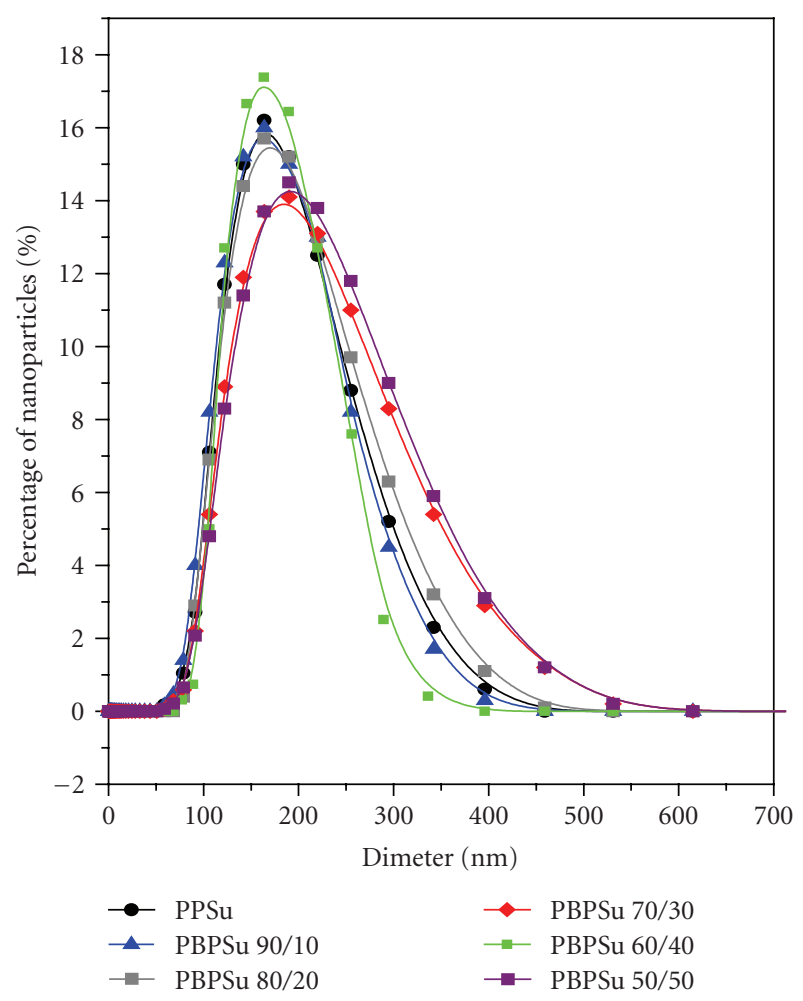

Figure 4: Particle size distribution of drug loaded PPBSu copolymer nanoparticles.

hydrophilic segments in the macromolecular chains, crystallinity, and so on [34]. All the samples had high nanoparticle yield, drug loading content, and entrapment efficiency, a fact that depends mainly on the intense hydrophobic character of Nimodipine. The percent loading of the PPBSu nanoparticles with Nimodipine achieved with the o/w solvent evaporation is comparable, or even better, with that obtained by $\varepsilon$-Caprolactone/L-lactide nanoparticles [35]. Table 3 shows how drug loading entrapment efficiency and nanoparticle yield are determined from the composition of the copolyester. It is obvious that an optimum ratio of the homopolymers PSu/BSu, between 90/10 and 80/20 can lead to the formation of copolyester that would give the best results for drug loading, entrapment efficiency and also the smaller nanoparticle size, but at the same time it is not possible to remark a systematic change of these parameters in cor- relation with $\mathrm{BSu} / \mathrm{PSu}$ ratio. At the same time the nanoparticle yield appears to be the highest in case of PPBSu 80/20.

\subsection{Physicochemical Characterization of Copolymer Nanoparticles}

3.4.1. Wide Angle X-Ray Diffractrometry (WAXD). Solid state of the prepared nanoparticles was characterized with WAXD. Figure 6 shows the WAXD patterns of pure Nimodipine, PPBSu 60/40 and 50/50 w/w Nimodipine loaded nanoparticles. The Nimodipine sample used for nanoparticles preparation was highly crystalline. The peaks observed in the WAXD pattern showed that the crystals were of modification I, as the pattern was identical to that reported by Grunenberg et al. for mod I crystals in their papers on polymorphism of the drug $[36,37]$. When Nimodipine was encapsulated into the polymeric nanoparticles the characteristic peaks of Nimodipine, did not appear in general in the patterns of the nanoparticles, except in case PPBSu 50/50 w/w was used. In the pattern of the PPBSu 50/50 w/w Nimodipine loaded nanoparticles, of Figure 6 the peaks for Nimodipine crystals are indicated by the arrows. Consequently, a small part of the encapsulated drug, still had the ability to create crystals into the matrix of the specific copolymer. This fact that does not fully agree with results previously reported for Nimodipine, which seems to appear as molecularly dispersed into the polymer matrix [33]. In the present case of PPBSu nanoparticles a great part of the drug disperses molecularly into the polymer matrix, but in the case of the crystallizing PPBSu 50/50 still Nimodipine, as highly hydrophobic drug, shows the ability of creating nanocrystals. Furthermore, from the peaks it is concluded that the crystals of Nimodipine were also of the same modification I, which in fact is the less stable $[36,37]$.

3.4.2. Fourier Transformation-Infrared Spectroscopy (FTIR). Figure 7 shows the FTIR spectra over the range of 900$1900 \mathrm{~cm}^{-1}$ for Nimodipine and PPBSu loaded nanoparticles. Nimodipine spectra show some characteristic peaks of the drug structure. At $1523 \mathrm{~cm}^{-1}$ appears the characteristic peak of $-\mathrm{NO}_{2}$ group and at $1695 \mathrm{~cm}^{-1}$ the characteristic absorption band of carbonyl group. Also appear at $1640 \mathrm{~cm}^{-1}$ the absorbance of the $\mathrm{C}=\mathrm{C}$ stretching and at $1620 \mathrm{~cm}^{-1}$ that of the aromatic $\mathrm{C}=\mathrm{C}$ stretches. The characteristic peaks of the drug were also obvious in the FTIR spectra of Nimodipine loaded PPBSu nanoparticles, but without any distinct shift. This fact verifies that nimodipine was entrapped into the 


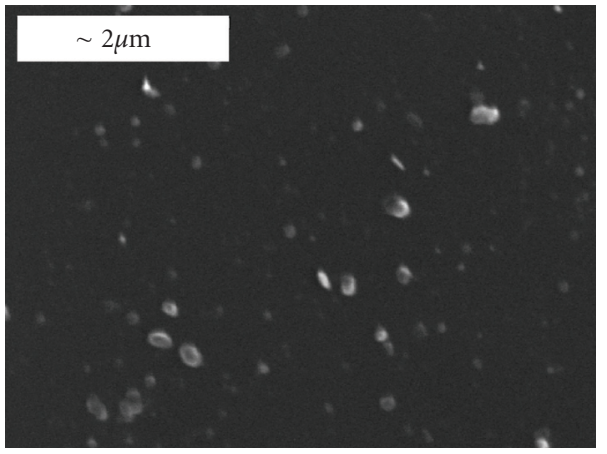

(a)

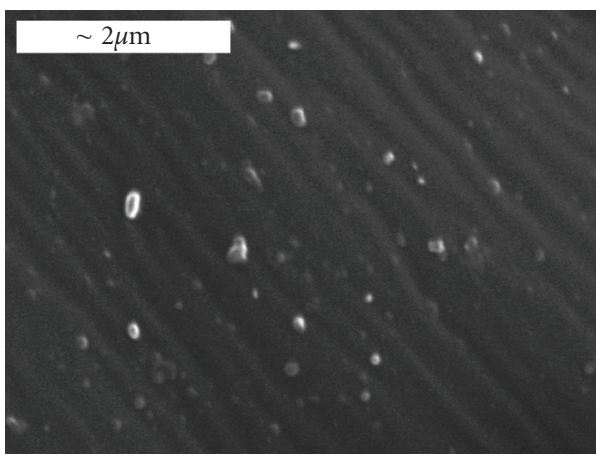

(b)

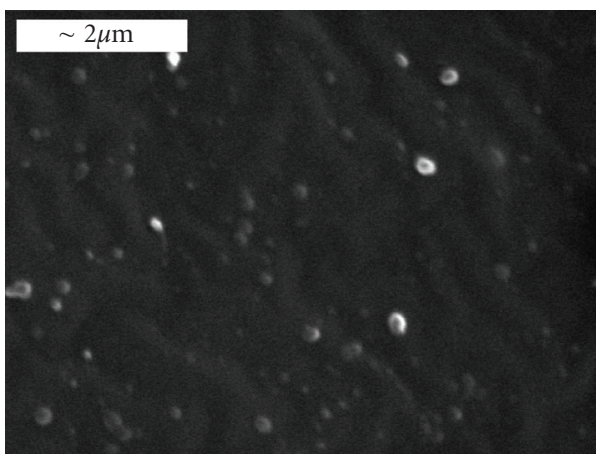

(c)

FIGURE 5: Scanning Electron Microscopy pictures of Nimodipineloaded PPBSu nanoparticles: (a) PPSu, (b) PPBSu 90/10 w/w and (c) PPBSu 50/50 w/w copolymer nanoparticles.

polymer matrix, but on the other hand it means that no chemical interaction between the drug and the polymer can be justified. A similar result has been previously reported [34].

3.5. In Vitro Drug Release Behavior. The most important feature of drug loaded polymer nanoparticles is connected with the ability to modify the release profile of the specific drug. Figure 8 shows the release profiles of Nimodipine from nanoparticles prepared using PPBSu copolymers with various $\mathrm{PSu} / \mathrm{BSu}$ weight ratios as well as from PPSu

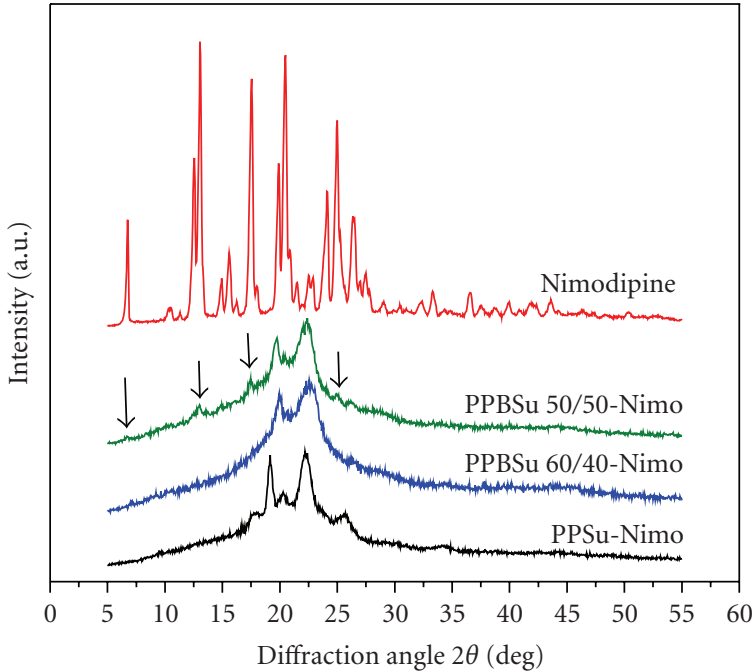

FIgUre 6: WAXD patterns of Nimodipine, PPBSu 50/50 and PPBSu 50/50 w/w Nimodipine loaded nanoparticles. Arrows show diffractions of Nimodpine crystals.

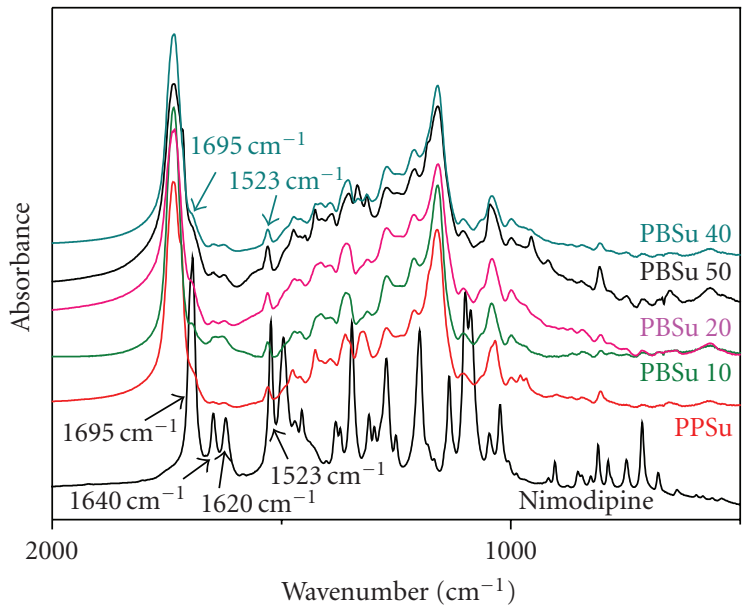

FIgure 7: Infrared spectra of Nimodipine, PPSu and PPBSu 90/10, 20/80, 40/60 and 50/50 w/w Nimodipine-loaded nanoparticles.

homopolymer nanoparticles. The results are illustrated as plots of the release percentages of Nimodipine based on loading amount, versus time. The release of the drug from the polymer nanoparticles has been characterized by many groups as a rather complicated process [38]. It can be affected by many factors, such as the polymer degradation, molecular weight, crystallinity and glass transition temperature of the polymer, as well as the binding affinity between the drug and the polyester matrix, the capability of the polymer to incorporate a great amount of the drug, the size of the nanoparticles, the hydrophilicity or hydrophobicity of the drug and so on $[34,39,40]$. Nevertheless, always only one or two of the above mentioned factors would mainly determine the drug release behavior of the nanoparticles.

Most of the drug loaded nanoparticle formulations show a biphasic release pattern in which an initial burst is followed by a sustained release $[41,42]$. The high initial release is 


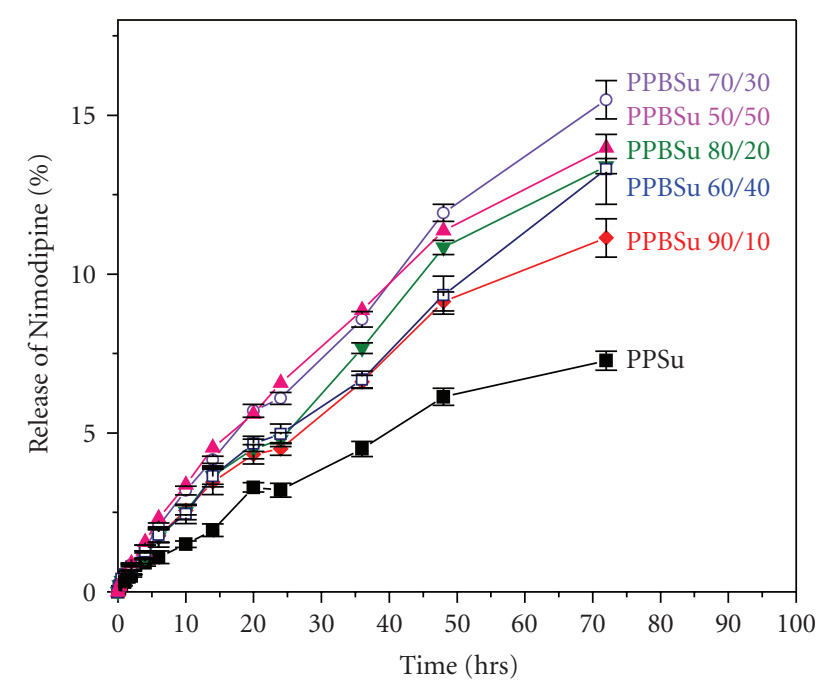

FIGURE 8: Nimodipine release profiles from PPBSu nanoparticles.

considered to happen due to the presence of free or weakly bound drug on the surface of particulate carriers. PPBSu nanoparticles do not show the characteristic burst effect. Such a behavior has been previously reported for other nanoparticles [33]. Absence of an initial burst justifies that there was little or negligible amount of surface located drug in these nanoparticles and the majority of Nimodipine was entrapped mainly in the interior of the polymer matrix. Also the probable existence of nanocrystals of the hydrophobic drug in nanoparticles, as was verified by XRD pattern in case of PPBSu 50/50, might lead to the suppression of water diffusion into the core of the nanoparticles and reversely Nimodipine diffusion into water. Such a process results in a slow release rate of the drug has also been previously reported [34].

A factor that might also have a key role in the release profile of Nimodipine is the polymer composition and as a result the crystallinity, melting point and $T_{g}$ which can largely affect the release of the drug from the polymer matrix to the dissolution medium [43]. High crystallinity could lead to formation of a microchannel structure, and at the same time the great surface area of the polymer matrix could cause the drug to be released easily from the nanoparticles [44]. However, in the case of PPBSu copolymers, crystallinity does not seem to have such an effect on the release of Nimodipine. In fact, those PPBSu copolymers with low melting points and low crystallinity, and especially amorphous ones gave nanoparticles from which the release of Nimodipine seems to have a slightly enhanced release rate. A low melting point, close to the temperature of dissolution tests, means significant chain mobility, even in the crystalline phase $[45,46]$. As a matter of fact, even in the case of PPBSu $60 / 40$ and $50 / 50 \mathrm{w} / \mathrm{w}$ which showed some crystallinty, only defective tiny crystals can be formed due to the lack of symmetry along the copolymer chains. And furthermore the particular copolymers formed PBSu type crystals, although $\mathrm{BSu}$ is the minor component. In case of copolymers with large comonomer content, poor packing is expected to affect both crystalline and amorphous phase, leading to increased free volume. Increased free volume and chain mobility, allows easier diffusional processes in the interior of the nanoparticles. The results of release profiles probably are not extended enough, in time, in order to have a more clear view on how the copolyester composition may probably affect the release rate of the drug. Unfortunately, lack of time in the availability and use of the dissolution apparatus and HPLC instrument as well as the chemical and physical instability of Nimodipine drug in the release medium, did not allow a more extended, in time, experiment.

It is a fact that there was not a clear differentiation of the release profiles of the copolymers and that is because the drug loadings as well as the micelle sizes of the different copolyesters is very close. Also the relatively high values of polydispersity index of the nanoparticle samples mean that actual sizes of different batches are similar and overlapping may be expected. As a result the release profiles of the copolyesters samples are much alike and they do not seem to give uniformity at the release profiles that would correlate with the chemical composition of the polymer matrix.

The experimental procedure that was followed for the release profile of the nanoparticles, with the use of cellulose membrane, does not allow the measurement of the nanoparticle size during experiment. Nevertheless the results from a previous study where the degradation of these polymers was studied [30] give us the strong impression that the release profile of these nanoparticles is a combination of diffusion mainly and in an explicitly smaller degree due to the degradation of the polymer matrix. As the degradation of these nanoparticles appears to be in such a limited extent, for the time of the in vitro release experiment, it can be probably considered negligible.

3.6. Kinetic Modeling of Drug Release. The dissolution profile of all formulations was fitted to Zero order, First order, Higuchi, Hixson-Crowell, and Korsmeyer-Peppas models [47], to ascertain the kinetic modeling of drug release (Table 1). All curve fittings, simulation and plotting, were carried out by using commercially available software, Sigma Plot version 8 , Systat software, Inc.

The magnitude of the release exponent $(n)$ in KorsmayerPeppas model indicates the release mechanism. (i.e., for Fickian diffusion, case II transport or anomalous transport). In the present study for polymeric sphere particles, the limits considered were $n \leq 0.43$ for a classical Fickian diffusion-controlled drug release, $n=0.85$ for case II relaxation release transport, non Fickian, zero order release, and values between $0.43<n<0.85$ can be regarded as an indicator of both phenomena (drug diffusion in the hydrated matrix and polymer relaxation) commonly called anomalous transport [47]. The correlation coefficient $(R)$ was used as an indicator of the best fitting of the models considered (Table 4). The release of Nimodipine (Figure 8) apparently follows Korsmeyer-Peppas model $(R>0.99)$ and zero-order kinetics $(R>0.99)$, respectively. From the results in the release exponent for Korsmayer-Peppas model (0.43 > $n>0.85$ ), it can be suggested that the mechanism that led to the release of Nimodipine was an anomalous transport 
TABLE 4: Dissolution parameters for all formulations.

\begin{tabular}{|c|c|c|c|c|c|c|c|c|c|c|c|}
\hline \multirow{2}{*}{ Formulation } & \multicolumn{3}{|c|}{ Korsmeyer-Peppas } & \multirow{2}{*}{$\begin{array}{l}\text { Zero- } \\
\text { Order } \\
K_{o}\end{array}$} & \multirow[b]{2}{*}{$R^{2}$} & \multirow{2}{*}{$\begin{array}{l}\text { Higuchi } \\
K_{H}\end{array}$} & \multirow[b]{2}{*}{$R^{2}$} & \multirow{2}{*}{$\begin{array}{l}\text { First- } \\
\text { Order } \\
K_{0}\end{array}$} & \multirow[b]{2}{*}{$R^{2}$} & \multirow{2}{*}{$\begin{array}{l}\text { Hixon and } \\
\text { Croweel } \\
K_{S}\end{array}$} & \multirow[b]{2}{*}{$R^{2}$} \\
\hline & (n) & $K_{K P}$ & $R^{2}$ & & & & & & & & \\
\hline PPSu & 0.75 & $\begin{array}{l}0.3087 \pm \\
0.2407\end{array}$ & 0.9952 & $\begin{array}{l}0.1073 \pm \\
0.2541\end{array}$ & 0.9851 & $\begin{array}{l}0.7545 \pm \\
0.6250\end{array}$ & 0.9641 & $\begin{array}{l}0.0012 \pm \\
0.4764\end{array}$ & 0.9793 & $\begin{array}{l}0.0004 \pm \\
0.4878\end{array}$ & 0.9783 \\
\hline $\begin{array}{l}\text { PPBSu } \\
90 / 10 \mathrm{w} / \mathrm{w}\end{array}$ & 0.76 & $\begin{array}{l}0.4398 \pm \\
0.2765\end{array}$ & 0.9972 & $\begin{array}{l}0.1614 \pm \\
0.2684\end{array}$ & 0.9889 & $\begin{array}{l}1.1281 \pm \\
0.9381\end{array}$ & 0.9640 & $\begin{array}{l}0.0018 \pm \\
0.6113\end{array}$ & 0.9849 & $\begin{array}{l}0.0006 \pm \\
0.6363\end{array}$ & 0.9836 \\
\hline $\begin{array}{l}\text { PPBSu } \\
80 / 20 \mathrm{w} / \mathrm{w}\end{array}$ & 0.85 & $\begin{array}{l}0.3647 \pm \\
0.3883 \\
\end{array}$ & 0.9961 & $\begin{array}{l}0.1942 \pm \\
0.3874\end{array}$ & 0.9934 & $\begin{array}{l}1.2955 \pm \\
1.3728\end{array}$ & 0.9458 & $\begin{array}{l}0.0022 \pm \\
0.4917 \\
\end{array}$ & 0.9932 & $\begin{array}{l}0.0007 \pm \\
0.5197\end{array}$ & 0.9924 \\
\hline $\begin{array}{l}\text { PPBSu } \\
70 / 30 \mathrm{w} / \mathrm{w}\end{array}$ & 0.81 & $\begin{array}{l}0.4825 \pm \\
0.2506\end{array}$ & 0.9987 & $\begin{array}{l}0.2203 \pm \\
0.3411\end{array}$ & 0.9946 & $\begin{array}{l}1.4995 \pm \\
1.4074\end{array}$ & 0.9558 & $\begin{array}{l}0.0025 \pm \\
0.5489\end{array}$ & 0.9934 & $\begin{array}{l}0.0008 \pm \\
0.5928\end{array}$ & 0.9923 \\
\hline $\begin{array}{l}\text { PPBSu } \\
60 / 40 \mathrm{w} / \mathrm{w}\end{array}$ & 0.84 & $\begin{array}{l}0.3652 \pm \\
0.2581 \\
\end{array}$ & 0.9980 & $\begin{array}{l}0.1815 \pm \\
0.2553 \\
\end{array}$ & 0.9966 & $\begin{array}{l}1.2332 \pm \\
1.2031 \\
\end{array}$ & 0.9522 & $\begin{array}{l}0.0020 \pm \\
0.4437 \\
\end{array}$ & 0.9936 & $\begin{array}{l}0.0007 \pm \\
0.4649 \\
\end{array}$ & 0.9930 \\
\hline $\begin{array}{l}\text { PPBSu } \\
50 / 50 \mathrm{w} / \mathrm{w}\end{array}$ & 0.72 & $\begin{array}{l}0.6567 \pm \\
0.2504\end{array}$ & 0.9986 & $\begin{array}{l}0.2041 \pm \\
0.3 .874\end{array}$ & 0.9853 & $\begin{array}{l}1.4561 \pm \\
1.0464\end{array}$ & 0.9723 & $\begin{array}{l}0.0024 \pm \\
0.8731\end{array}$ & 0.9808 & $\begin{array}{l}0.0008 \pm \\
0.9185\end{array}$ & 0.9787 \\
\hline
\end{tabular}

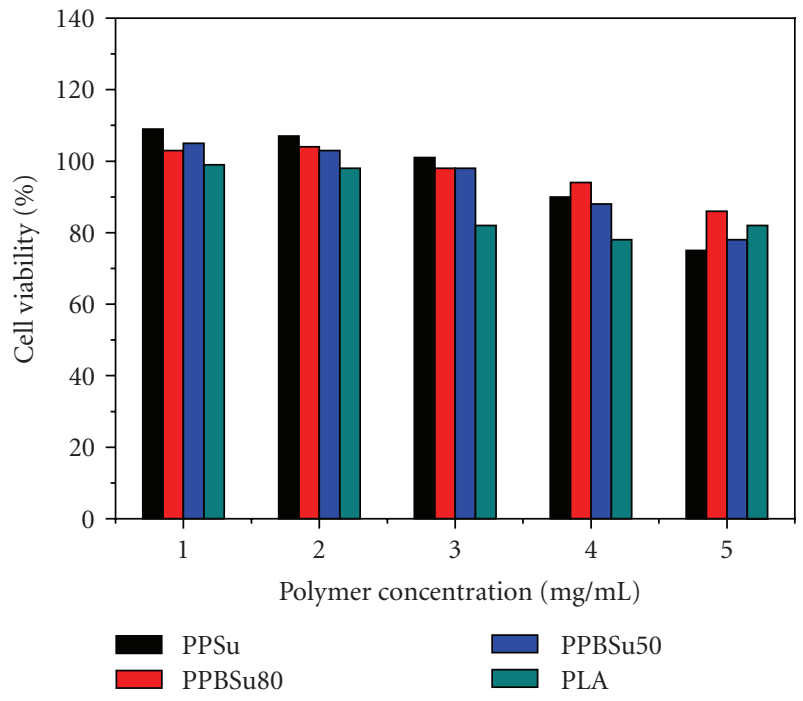

FIGURE 9: HUVEC cells viability after incubation for 24 hours with different concentrations of PPSu, PPBSu copolymers in comparison to PLA.

with constant release rate adequate for a sustained release dosage form. However, looking at the negligible variation of $(R)$ values for the release of Nimodipine, the release rate date analysis applying these mathematical models can be purely imperial, and no definitive conclusion can be drawn concerning the dominating mass transport mechanism.

3.7. In Vitro Biocompatibility of PPBSu Copolymers. From our previous study it was found that PPSu is a biocompatible polymer and thus it can be used as possible drug carrier [19]. As can be seen in Figure 9 PPSu polymer exhibited low toxicity against HUVEC cells, with appreciable cytotoxicity (less than 20\% reduction of cell viability) being observed only after exposing the cells at high nanoparticle concentrations. Based on the viability of HUVEC cells in the presence of the polymer (Figure 9), the biocompatibility of PPSu is comparable to that of PLA, which is a polymer of high biocompatibility and widely used in biomedical applications [48]. The prepared PPBSu copolymers have also similar cytotoxicity with PPSu, and thus it can be concluded that these are also biocompatible polymers.

\section{Conclusions}

Novel poly(propylene-co-butylene succinate) copolyesters containing more than $50 \mathrm{~mol} \%$ propylene succinate units synthesized from direct esterification of 1,3-propanediol and 1,4-butanediol with succinic acid, were found to be biocompatible. Neat PPSu and PPBSu copolymers showed low toxicity to HUVEC cells. Their behaviour was similar to poly(lactic acid).

PPBSu copolyesters were semicrystalline, with low melting points close to the human body temperature and a glass transition temperature close to $-35^{\circ} \mathrm{C}$.

Copolymer nanoparticles loaded with the calcium antagonist Nimodipine were prepared, showing satisfactory drug loading, encapsulation efficiency and yield. These parameters seem to be influenced by the composition of the copolyesters, giving the best results for the sample of PPBSu 90/10. Physicochemical characterization of the drug loaded nanoparticles showed that Nimodipine is molecularly dispersed in the polymer matrix. In an extreme case, still tiny crystals can be identified in the XRD patterns. As a matter of fact, interactions between the polyesters and the drug cannot be justified from FTIR spectra.

\section{Acknowledgment}

This work was funded by the Greek Ministry of Education through the postdoctoral research program EPEAEK Pythagoras I. 


\section{References}

[1] I. Briger, C. Dubernet, and P. Couvreur, "Nanoparticles in cancer therapy and diagnosis," Advanced Drug Delivery Reviews, vol. 54, pp. 631-651, 2002.

[2] G. Barratt, "Colloidal drug carriers: achievements and perspectives," Cellular and Molecular Life Sciences, vol. 60, no. 1, pp. 21-37, 2003.

[3] P. Couvreur and C. Vauthier, "Nanotechnology: intelligent design to treat complex disease," Pharmaceutical Research, vol. 23, no. 7, pp. 1417-1450, 2006.

[4] A. M. de Campos, Y. Diebold, E. L. S. Carvalho, A. Sánchez, and M. J. Alonso, "Chitosan nanoparticles as new ocular drug delivery systems: in vitro stability, in vivo fate, and cellular toxicity," Pharmaceutical Research, vol. 21, no. 5, pp. 803-810, 2004.

[5] A. H. Krauland and M. J. Alonso, "Chitosan/cyclodextrin nanoparticles as macromolecular drug delivery system," International Journal of Pharmaceutics, vol. 340, no. 1-2, pp. 134 $142,2007$.

[6] K. Bowman and K. W. Leong, "Chitosan nanoparticles for oral drug and gene delivery," International Journal of Nanomedicine, vol. 1, no. 2, pp. 117-128, 2006.

[7] S. Papadimitriou, D. Bikiaris, K. Avgoustakis, E. Karavas, and M. Georgarakis, "Chitosan nanoparticles loaded with dorzolamide and pramipexole," Carbohydrate Polymers, vol. 73, no. 1, pp. 44-54, 2008.

[8] L. Brannon-Peppas, "Recent advances on the use of biodegradable microparticles and nanoparticles in controlled drug delivery," International Journal of Pharmaceutics, vol. 116, no. 1, pp. 1-9, 1995.

[9] K. S. Soppimath, T. M. Aminabhavi, A. R. Kulkarni, and W. E. Rudzinski, "Biodegradable polymeric nanoparticles as drug delivery devices," Journal of Controlled Release, vol. 70, no. 1-2, pp. 1-20, 2001.

[10] S.-S. Feng, "Nanoparticles of biodegradable polymers for newconcept chemotherapy," Expert Review of Medical Devices, vol. 1, no. 1, pp. 115-125, 2004.

[11] K. J. Ihn, E. S. Yoo, and S. S. Im, "Structure and morphology of poly(tetramethylene succinate) crystals," Macromolecules, vol. 28, no. 3, pp. 2460-2469, 1995.

[12] P. Rizzarelli, G. Impallomeni, and G. Montaudo, "Evidence of selective hydrolysis of aliphatic copolyesters induced by lipase catalysis," Biomacromolecules, vol. 5, no. 2, pp. 433-444, 2004.

[13] D. N. Bikiaris, G. Z. Papageorgiou, and D. S. Achilias, "Synthesis and comparative biodegradability studies of three poly(alkylene succinate)s," Polymer Degradation and Stability, vol. 91, no. 1, pp. 31-43, 2006.

[14] E. Ranucci, Y. Liu, M. S. Lindblad, and A.-C. Albertsson, "New biodegradable polymers from renewable sources. High molecular weight poly(ester carbonate)s from succinic acid and 1,3propanediol," Macromolecular Rapid Communications, vol. 21, no. 10, pp. 680-684, 2000.

[15] Y. Liu, E. Ranucci, M. S. Lindblad, and A.-C. Albertsson, "New biodegradable polymers from renewable sources: polyester-carbonates based on 1,3-propylene-co-1,4cyclohexanedimethylene succinate," Journal of Polymer Science Part A, vol. 39, no. 14, pp. 2508-2519, 2001.

[16] Y. Liu, M. S. Lindblad, E. Ranucci, and A.-C. Albertsson, "New segmented poly(ester-urethane)s from renewable resources," Journal of Polymer Science Part A, vol. 39, no. 5, pp. 630-639, 2001.
[17] M. Hartlep, W. Hussmann, N. Prayitno, I. Meynial-Salles, and A.-P. Zeng, "Study of two-stage processes for the microbial production of 1,3-propanediol from glucose," Applied Microbiology and Biotechnology, vol. 60, no. 1-2, pp. 60-66, 2002.

[18] D. Y. Kim, S. C. Yim, P. C. Lee, W. G. Lee, S. Y. Lee, and H. N. Chang, "Batch and continuous fermentation of succinic acid from wood hydrolysate by Mannheimia succiniciproducens MBEL55E," Enzyme and Microbial Technology, vol. 35, no. 6-7, pp. 648-653, 2004.

[19] D. N. Bikiaris, G. Z. Papageorgiou, S. A. Papadimitriou, E. Karavas, and K. Avgoustakis, "Novel biodegradable polyester poly(propylene succinate): synthesis and application in the preparation of solid dispersions and nanoparticles of a watersoluble drug," AAPS PharmSciTech, vol. 10, no. 1, pp. 138-146, 2009.

[20] S. S. Umare, A. S. Chandure, and R. A. Pandey, "Synthesis, characterization and biodegradable studies of 1,3-propanediol based polyesters," Polymer Degradation and Stability, vol. 92, no. 3, pp. 464-479, 2007.

[21] M. Soccio, L. Fineili, N. Lotti, M. Gazzano, and A. Munari, "Poly(propylene isophthalate), poly(propylene succinate), and their random copolymers: synthesis and thermal properties," Journal of Polymer Science Part B, vol. 45, no. 3, pp. 310-321, 2007.

[22] D. N. Bikiaris, K. Chrissafis, K. M. Paraskevopoulos, K. S. Triantafyllidis, and E. V. Antonakou, "Investigation of thermal degradation mechanism of an aliphatic polyester using pyrolysis-gas chromatography-mass spectrometry and a kinetic study of the effect of the amount of polymerisation catalyst," Polymer Degradation and Stability, vol. 92, no. 4, pp. 525-536, 2007.

[23] M. Soccio, A. Nogales, N. Lotti, A. Munari, and T. A. Ezquerra, "Evidence of early stage precursors of polymer crystals by dielectric spectroscopy," Physical Review Letters, vol. 98, no. 3, Article ID 037801, 4 pages, 2007.

[24] Y. Xu, J. Xu, B. Guo, and X. Xie, "Crystallization kinetics and morphology of biodegradable poly(butylene succinateco-propylene succinate)s," Journal of Polymer Science Part B, vol. 45, no. 4, pp. 420-428, 2007.

[25] D. N. Bikiaris and D. S. Achilias, "Synthesis of poly(alkylene succinate) biodegradable polyesters I. Mathematical modelling of the esterification reaction," Polymer, vol. 47, no. 13, pp. 4851-4860, 2006.

[26] M. Mochizuki, K. Mukai, K. Yamada, N. Ichise, S. Murase, and Y. Iwaya, "Structural effects upon enzymatic hydrolysis of poly(butylene succinate-co-ethylene succinate)s," Macromolecules, vol. 30, no. 24, pp. 7403-7407, 1997.

[27] M. D. I. Vergouwen, M. Vermeulen, R. J. de Haan, M. Levi, and Y. B. W. E. M. Roos, "Dihydropyridine calcium antagonists increase fibrinolytic activity: a systematic review," Journal of Cerebral Blood Flow and Metabolism, vol. 27, no. 7, pp. 12931308, 2007.

[28] K. Avgoustakis, A. Beletsi, Z. Panagi, P. Klepetsanis, A. Karydas, and D. Ithakissios, "PLGA-mPEG nanoparticles of cisplatin: in vitro nanoparticle degradation, in vitro drug release and in vivo drug residence in blood properties," Journal of Controlled Release, vol. 79, no. 1-3, pp. 123-135, 2002.

[29] A. Beletsi, L. Leontiadis, P. Klepetsanis, D. S. Ithakissios, and K. Avgoustakis, "Effect of preparative variables on the properties of poly(dl-lactide-co-glycolide)-methoxypoly(ethyleneglycol) copolymers related to their application in controlled drug delivery," International Journal of Pharmaceutics, vol. 182, no. 2, pp. 187-197, 1999. 
[30] G. Z. Papageorgiou and D. N. Bikiaris, "Synthesis, cocrystallization, and enzymatic degradation of novel poly(butyleneco-propylene succinate) copolymers," Biomacromolecules, vol. 8, no. 8, pp. 2437-2449, 2007.

[31] G. Z. Papageorgiou, D. Bikiaris, E. Karavas, et al., "Effect of physical state and particle size distribution on dissolution enhancement of nimodipine/PEG solid dispersions prepared by melt mixing and solvent evaporation," The AAPS Journal, vol. 8, no. 4, pp. E623-E631, 2006.

[32] A. Docoslis, K. L. Huszarik, G. Z. Papageorgiou, D. Bikiaris, A. Stergiou, and E. Georgarakis, "Characterization of the distribution, polymorphism, and stability of nimodipine in its solid dispersions in polyethylene glycol by micro-Raman spectroscopy and powder X-ray diffraction," The AAPS Journal, vol. 9, no. 3, pp. E361-E370, 2007.

[33] G. Mittal, D. K. Sahana, V. Bhardwaj, and M. N. V. Ravi Kumar, "Estradiol loaded PLGA nanoparticles for oral administration: effect of polymer molecular weight and copolymer composition on release behavior in vitro and in vivo," Journal of Controlled Release, vol. 119, no. 1, pp. 77-85, 2007.

[34] Y. Hu, X. Jiang, Y. Ding, et al., "Preparation and drug release behaviors of nimodipine-loaded poly(caprolactone)poly(ethylene oxide)-polylactide amphiphilic copolymer nanoparticles," Biomaterials, vol. 24, no. 13, pp. 2395-2404, 2003.

[35] H. Ge, Y. Hu, S. Yang, X. Jiang, and C. Yang, "Preparation, characterization, and drug release behaviors of drug-loaded $\varepsilon$-caprolactone/L-lactide copolymer nanoparticles," Journal of Applied Polymer Science, vol. 75, no. 7, pp. 874-882, 2000.

[36] A. Grunenberg, B. Keil, and J.-O. Henck, "Polymorphism in binary mixtures, as exemplified by nimodipine," International Journal of Pharmaceutics, vol. 118, no. 1, pp. 11-21, 1995.

[37] A. Grunenberg, J.-O. Henck, and H. W. Siesler, "Theoretical derivation and practical application of energy/temperature diagrams as an instrument in preformulation studies of polymorphic drug substances," International Journal of Pharmaceutics, vol. 129, no. 1-2, pp. 147-158, 1996.

[38] H. Ge, Y. Hu, X. Jiang, et al., "Preparation, characterization, and drug release behaviors of drug nimodipine-loaded poly $(\varepsilon-$ caprolactone)-poly(ethylene oxide)-poly( $\varepsilon$-caprolactone) amphiphilic triblock copolymer micelles," Journal of Pharmaceutical Sciences, vol. 91, no. 6, pp. 1463-1473, 2002.

[39] I. G. Shin, S. Y. Kim, Y. M. Lee, C. S. Cho, and Y. K. Sung, "Methoxy poly(ethylene glycol)/E-caprolactone amphiphilic block copolymeric micelle containing indomethacin. I. Preparation and characterization," Journal of Controlled Release, vol. 51, no. 1, pp. 1-11, 1998.

[40] R. Gref, Y. Minamitake, M. T. Peracchia, V. Trubetskoy, V. Torchilin, and R. Langer, "Biodegradable long-circulating polymeric nanospheres," Science, vol. 263, no. 5153, pp. 16001603, 1994.

[41] D. T. Birnbaum, J. D. Kosmala, D. B. Henthorn, and L. Brannon-Peppas, "Controlled release of $\beta$-estradiol from PLAGA microparticles: the effect of organic phase solvent on encapsulation and release," Journal of Controlled Release, vol. 65, no. 3, pp. 375-387, 2000.

[42] M. Otsuka, H. Uenodan, Y. Matsuda, T. Mogi, H. Ohshima, and K. Makino, "Therapeutic effect of in vivo sustained estradiol release from poly (lactide-co-glycolide) microspheres on bone mineral density of osteoporosis rats," Bio-Medical Materials and Engineering, vol. 12, no. 2, pp. 157-167, 2002.
[43] H. Ge, Y. Hu, S. Yang, X. Jiang, and C. Yang, "Preparation, characterization, and drug release behaviors of drug-loaded $\varepsilon$-caprolactone/L-lactide copolymer nanoparticles," Journal of Applied Polymer Science, vol. 75, no. 7, pp. 874-882, 2000.

[44] S. Izumikawa, S. Yoshioka, Y. Aso, and Y. Takeda, "Preparation of poly (L-lactide) microspheres of different crystalline morphology and effect of crystalline morphology on drug release rate," Journal of Controlled Release, vol. 15, no. 2, pp. 133-140, 1991.

[45] D. Bikiaris, V. Karavelidis, and E. Karavas, "Novel biodegradable polyesters. Synthesis and application as drug carriers for the preparation of raloxifene $\mathrm{HCl}$ loaded nanoparticles," Molecules, vol. 14, no. 7, pp. 2410-2430, 2009.

[46] S. Papadimitriou and D. Bikiaris, "Novel self-assembled coreshell nanoparticles based on crystalline amorphous moieties of aliphatic copolyesters for efficient controlled drug release," Journal of Controlled Release, vol. 138, no. 2, pp. 177-184, 2009.

[47] P. Costa and J. M. Sousa Lobo, "Modeling and comparison of dissolution profiles," European Journal of Pharmaceutical Sciences, vol. 13, no. 2, pp. 123-133, 2001.

[48] K. A. Athanasiou, G. G. Niederauer, and C. M. Agrawal, "Sterilization, toxicity, biocompatibility and clinical applications of polylactic acid/polyglycolic acid copolymers," Biomaterials, vol. 17, no. 2, pp. 93-102, 1996. 

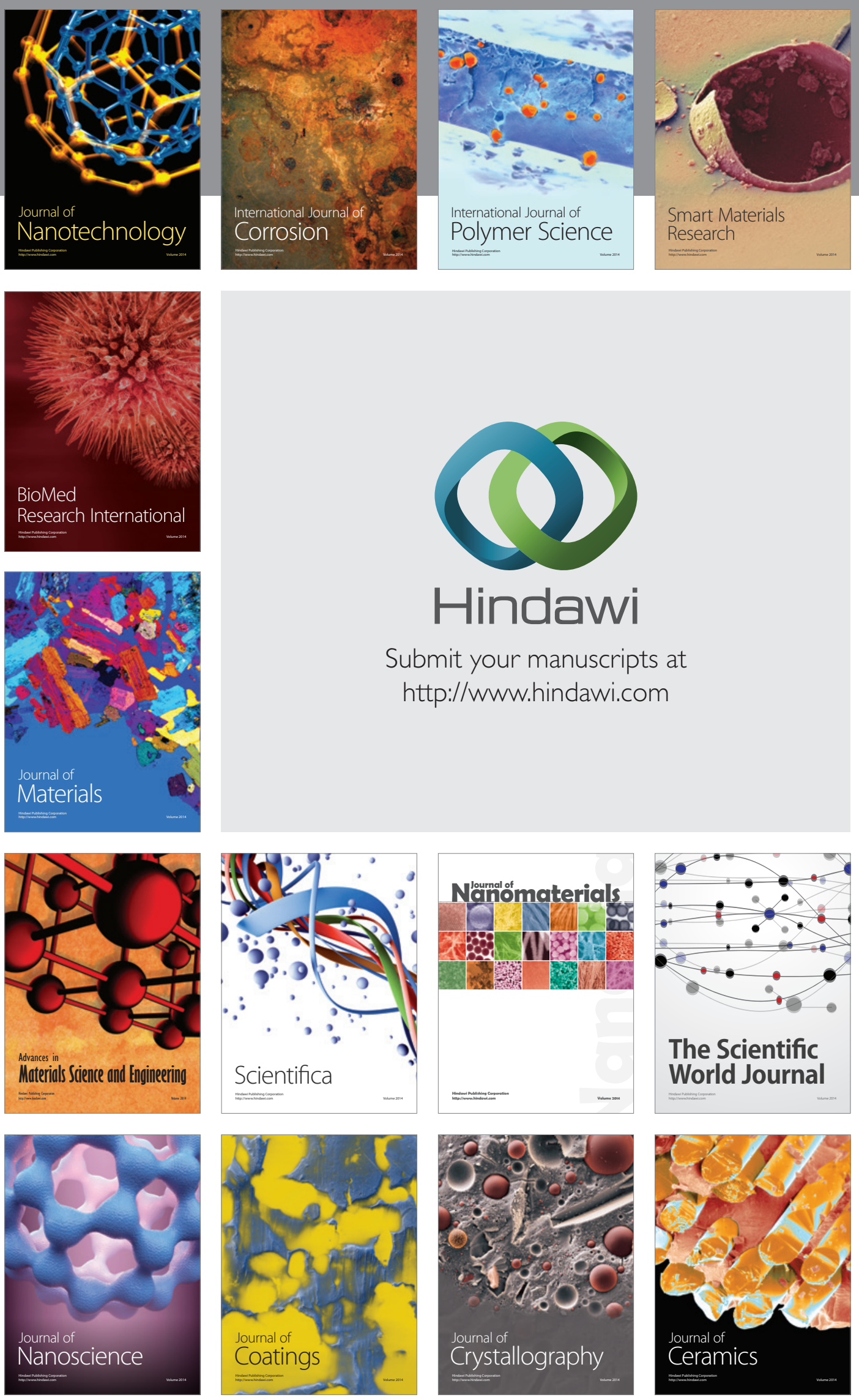

The Scientific World Journal

Submit your manuscripts at

http://www.hindawi.com

\section{World Journal}

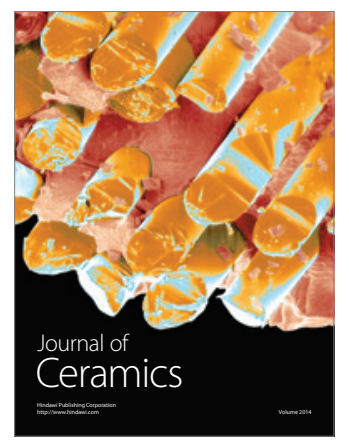

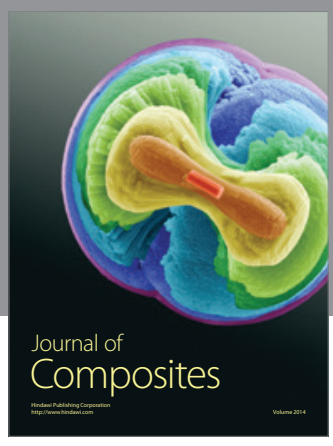
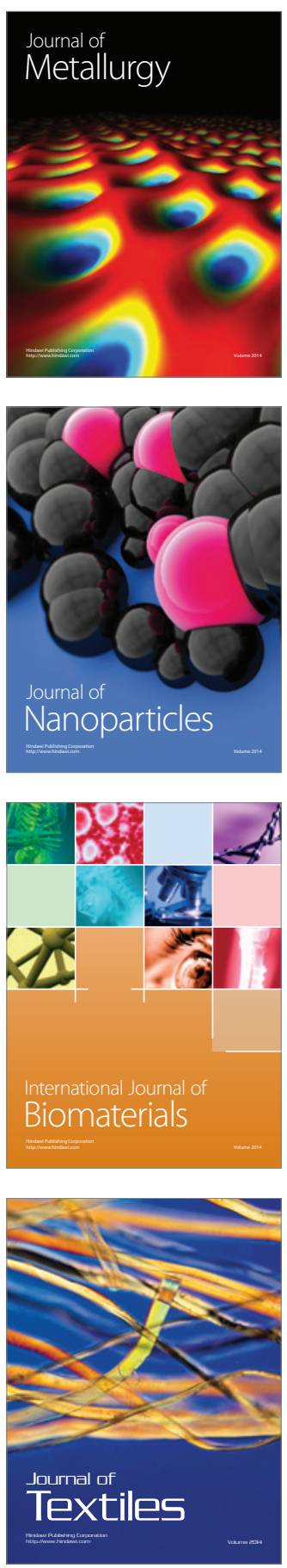